\title{
Induction of different types of callus in Jatropha curcas L. hybrid accession at in vitro condition
}

\author{
Alexandre Bosco de Oliveira ${ }^{1^{*}}$, Wagner A. Vendrame ${ }^{2}$, Luciana Cardoso Nogueira Londe ${ }^{3}$, Massy \\ Sanaey $^{2}$ \\ ${ }^{1}$ Federal University of Ceará, Department of Crop Science, Center of Agricultural Sciences, Av. Mister Hull, \\ 2977, Fortaleza, CE, 60356-001, Brazil \\ ${ }^{2}$ University of Florida, Tropical Research and Education Center, $18905 \mathrm{SW} 280^{\text {th }}$ St. Homestead, FL, 33031, USA \\ ${ }^{3}$ Agricultural Research Company of Minas Gerais State, Brazil, Rodovia MGT 122, m 155, Campo Experimental \\ do Gorutuba, Nova Porteirinha, MG, 39.525-000, Brazil
}

*Correspondent author: aleufc@gmail.com

\begin{abstract}
Micropropagation protocols depend on several factors, particularly on the types, combinations, and levels of plant growth regulators used in the culture media. The aim of this study was to determine the influence of 6-Benzylaminopurine (BAP) and Naphtalen-3acetic acid (NAA) concentrations on callus induction of Jatropha curcas L. explants. The plant material used was a jatropha hybrid accession developed through intraspecific crosses between Costa Rica and Mexico genetic resources (TREC 49 x TREC 33 accession codes). Callus cultures were initiated from hypocotyl explants isolated from 15-days-old seedlings, on Murashige and Skoog (MS) basal medium supplemented with $0 ; 2$ or $4 \mathrm{mg} \mathrm{L}^{-1} \mathrm{BAP}$ and $0 ; 1$ or $2 \mathrm{mg} \mathrm{L}^{-1} \mathrm{NAA}$ in different combinations. Better-quality callus formation was obtained in medium supplemented with BAP $2 \mathrm{mg} \mathrm{L}^{-1}$ and NAA $1 \mathrm{mg} \mathrm{L}^{-1}$. This combination of plant growth regulators resulted in higher amount of white colored and friable calli, which are more likely to differentiate in bud shoots and roots, depending upon the plant growth regulations added to the media. Our results suggest that BAP $\left(2 \mathrm{mg} \mathrm{L}^{-1}\right)$ and NAA $\left(1 \mathrm{mg} \mathrm{L} \mathrm{L}^{-1}\right)$ combined can be used for in vitro callogenesis of J. curcas hybrid accession and that it can be adapted to a large-scale in vitro mass production system or to support biotechnological protocols.
\end{abstract}

Keywords: Micropropagation, Energy crops, 6-Benzylaminopurine, 1-Naphthaleneacetic acid.

Abbreviations: BAP_6-Benzylaminopurine, MS_Basal culture medium (Murashige and Skoog, 1962), NAA_1-Naphthaleneacetic acid, IBA_Indole-3-butyric acid.

\section{Introduction}

Among the energy crops, Jatropha curcas L. has emerged as the most promising tree-borne oilseed not only because of its high-quality oil that can be used as a biodiesel, but also due to its adaptability to a wide range of edapho-climatic conditions, whereas provides soil erosion control. Thus, Parthiban et al. (2011) emphasized that tree-borne oilseeds are the best and potential alternative to mitigate the current and future energy crisis and to transform the vast stretches of wasteland into green oil fields. One of the limitations in the jatropha breeding materials is the low or incomplete information about the germplasm resources (Maghuly et al., 2015). According to Santos et al. (2016), this highlights the importance of generating more information on the international jatropha collections, for a better exploitation of the species as an energy source that may benefit resource poor farmers. Among the international collections of jatropha, the University of Florida gene bank contains various accessions of different origin. Studying the population of this collection, Nietsche et al. (2013) and Santos et al. (2016) confirmed that Costa Rican and Mexican accessions can be used as potential parents in breeding programs of jatropha because they showed a high level of genetic diversity. The distinctness and high genetic diversity of Mexican accessions has also been reported by Pecina-
Quintero et al. (2011) in Mexico. Regarding J. curcas domestication, Dikavara et al. (2010) warn that priority should be given to assess intra- and inter-accessional variability in the available germplasm, selection of pure lines and then multiplication. In addition, Morinuzzaman et al. (2016) believe that it is time to investigate somaclonal variation, in vitro selection and haploid breeding for physic nut improvement. Callus induction, culture and regeneration optimization in vitro are important steps in the process of plant propagation and genetic transformation. Therefore, efficient callus induction and in vitro regeneration system is highly required to enhance the use of modern techniques in genetic improvement (Pan et al., 2010; Jose et al., 2012). In addition, callogenesis studies can be considered as part of an important field of research that can help with the conduction of microgravity experiments during long-term missions in space, once this require small amount of space and plant material, providing rapid results afterwards. Vendrame and Pinares (2013), provided the basic ground work and preflight assessment needed to justify a model for microgravity studies with jatropha in vitro cell cultures. According to these authors, future studies should focus on investigating the results of experiments with jatropha in vitro cell cultures in 
microgravity, including culture growth, and potential genetic changes and differential gene expression.

Among the factors that can be controlled throughout process of in vitro callus induction, the plant growth regulators (PGR) can be considered as one of the most important ones. Two relevant classes of PGRs that are used to control organ and tissue development are the auxins and cytokinins (Ismail et al., 2013) and an appropriated cytokinin/auxin balance for each in vitro purpose can benefits the evaluation of jatropha hybrid accessions. This can allow the researchers to achieve their goals faster, taking advantage of their traits through the mass propagation of specific clones or plant genetic transformation, enhancing this species domestication process. In this context, the novelty of the present work is based on the investigation of PGRs effects on callus formation in a promising jatropha hybrid accession never studied before. Our results, therefore, provide relevant information which can benefit further researches on breeding and biotechnological techniques that play a major role to accelerate this species domestication process. Thus, the objective of this study was to evaluate the effects of BAP and NAA concentrations on callus induction from Jatropha curcas L. explants.

\section{Results}

\section{Effect of BAP and NAA combinations on callus induction ( $1^{\text {st }}$ assessment)}

The concentration of BAP and NAA in the medium significantly influenced the response of induction of callus. Although there was no isolated effected of NAA levels on number of white colored and friable induced calli $(\mathrm{P}>0.01)$, it was inversely proportional to BAP concentration under NAA $1 \mathrm{mg} \mathrm{L}^{-1}$ (Fig 1A). Thus, a fewer number of these calli per jar was observed under NAA $1 \mathrm{mg} \mathrm{L}^{-1}$ and BAP $4 \mathrm{mg} \mathrm{L}^{-1}$ combination $(\mathrm{P}>0.01)$, whereas the other PGR combinations did not differ statistically among themselves. Not coincidently, the mentioned combination resulted in a higher number of compact and light green calli per jar, which have opposite features when compared to the white colored and friable ones and, therefore, lower chances to differentiate (Fig $1 \mathrm{C})$.

The absence of NAA resulted in absence of induction of two calli types, which were both cream colored and friable and compact and green light ones (Fig 1B and 1C). However, while for this first type the callus induction was directly proportional to NAA concentration under BAP presence (Fig $1 \mathrm{~B})$, the second one was directly proportional to BAP concentration under NAA $1 \mathrm{mg} \mathrm{L}^{-1}$ (Fig 1C).

The number of oxidized calli was inversely proportional to NAA concentrations under BAP $1 \mathrm{mg} \mathrm{L}^{-1}$ (Fig 1D). On the other hand, the absence of BAP, combined with NAA absence or in lower concentration (NAA 0 or $1 \mathrm{mg} \mathrm{L}^{-1}$ ), resulted in no oxidized callus induction.

\section{Effect of BAP and NAA combinations on callus induction ( $2^{\text {nd }}$ assessment)}

After 26 days of experiment, we observed that, in general, the induction of both white colored and cream colored and friable calli were directly proportional to PGRs concentration (Fig 2A and 2B). It is showed on Fig 2C a substantial increment in compact and light green callus induction growing in MS media supplemented with intermediate concentrations of both PGRs evaluated (BAP 0 or $2 \mathrm{mg} \mathrm{L}^{-1}$ combined with NAA $1 \mathrm{mg} \mathrm{L}^{-1}$ ). Hence, this variable followed the same behavior observed on 13 days of experiment (Fig $2 \mathrm{C})$, just increasing its amount when compared to the first assessment.

After 56 days of in vitro culture, the number of oxidized callus were still low, which did not show a clear pattern through the different PGR combinations (Fig 2D). Nevertheless, just like in the first assessment, none oxidized calli induction was verified in standard MS media, which means cultured in vitro under absence of both phytoregulators.

\section{Effect of dark conditions on callus growth}

Although there were no differentiation effects on prestablished calli in vitro for this experiment, we did observe relevant differences on types of callus formed after 30 days and in absence of PGRs, under dark conditions. There was practically no induction of either white, cream or light green callus from those ones previously cultivated in BAP-absent medium (Fig 3A, 3B and 3C). On the other hand, for those first ones is evident that the higher the PGR concentration in first medium (BAP 2 or $4 \mathrm{mg} \mathrm{L}^{-1}$ x NAA $2 \mathrm{mg} \mathrm{L}^{-1}$ ), the higher these calli induction in the new medium.

Despite of a decline in compact and green light callus formation for most treatments throughout the time (Fig 3C and $2 \mathrm{C}$ ), contrasting behavior was observed for the number of oxidized callus (Fig 3D and 2C), with significant increments.

In general, among the treatments evaluated, we observed that BAP $\left(2 \mathrm{mg} \mathrm{L}^{-1}\right)$ and NAA $\left(1 \mathrm{mg} \mathrm{L}^{-1}\right)$ is the best combination of these growth regulators to obtain goodquality callus of $J$. curcas hybrid accession.

\section{Discussion}

The results obtained in this study show that there is a great potential in the utilization of BAP and NAA combinations to provide in vitro induction of $J$. curcas callus. Callus formation was observed within one to two weeks on leaf explants cultured on MS basal medium supplemented with varying concentrations of PGRs. Callusing was initiated between 6 and 10 days of inoculation, following similar behavior observed by other authors who worked with induction of callus in jatropha explants in vitro (Rajore and Batra, 2007; Kumar et al., 2008). The present study resulted in different types of callus induction. To get this goal achieved, many the choice of growth regulators and explants was essential for successful somatic embryogenesis. Hence, BAP and NAA in low or medium concentrations provided good amount of callus induction in vitro for this material. Similar behavior was observed by Mohajer et al. (2012), whose results of the different PGRs combinations and concentrations showed that BAP and NAA combined were better than BAP and IBA for callus production. In general, our results showed relevant induction of white, cream and light green calli in medium supplemented with NAA $1 \mathrm{mg} \mathrm{L}$ 1 . Rajore and Batra (2007) also found NAA as being the best PGR for producing green, compact and fast growing jatropha callus. According to these author's considerations, the optimal concentration for this auxin was also $1 \mathrm{mg} \mathrm{L}^{-1}$, agreeing, therefore, with the present experiment. Many recent studies in the literature have reported the necessity of an ideal combination cytokinin and auxin to produce jatropha callus (Biradar et al., 2012; Costa et al., 2015; Kumar et al., 2015). 
A

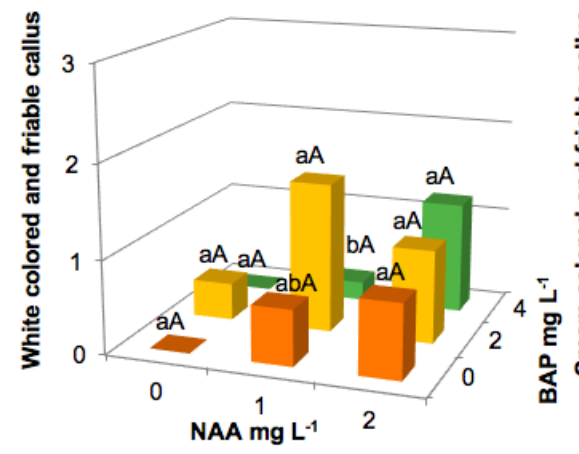

C

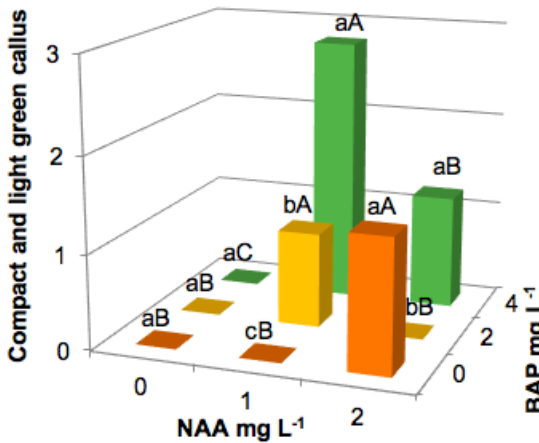

B

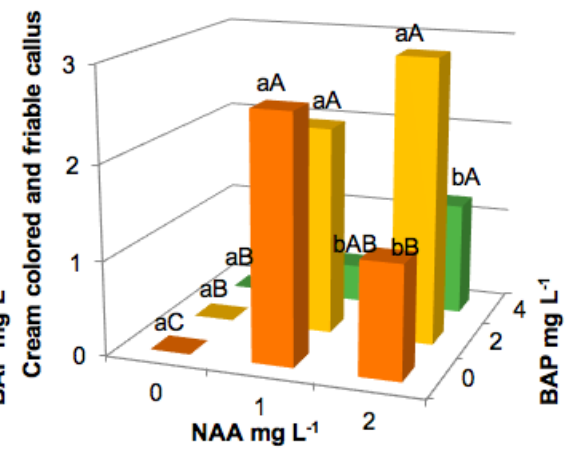

D

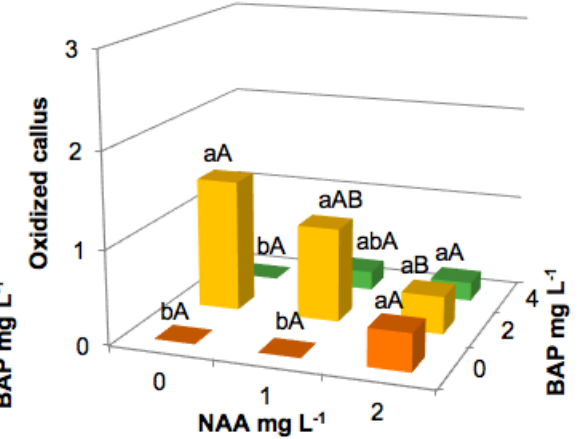

Fig 1. Calli formation from in vitro jatropha explants 13 days after inoculation in Murashige and Skoog (MS) basal medium with different concentrations of alpha-naphthalene acetic acid (NAA) and 6-Benzylaminopurine (BAP). Within each plant growth regulator, bars labeled with the same uppercase letter for NAA or lowercase letter for BAP are not significantly different $(P=0.01)$.

A

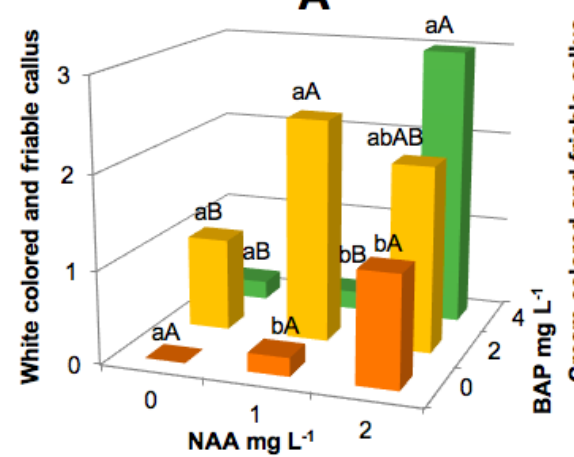

C

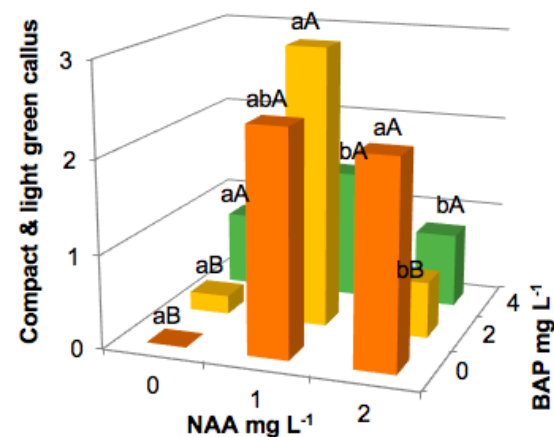

B

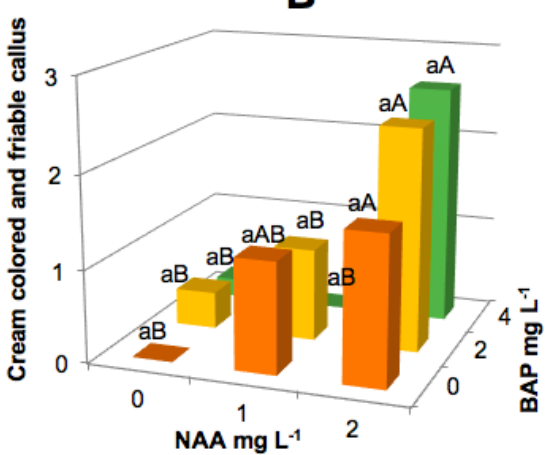

D

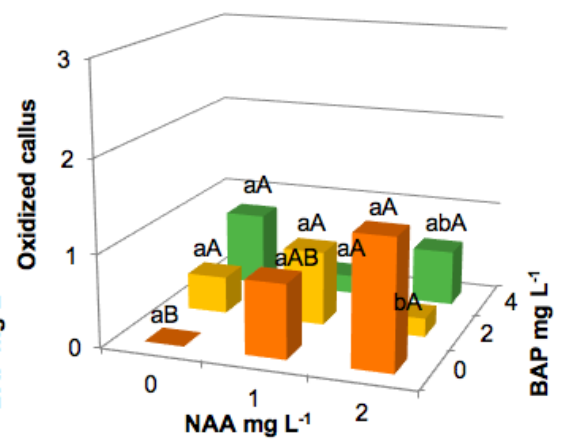

Fig 2. Calli formation from in vitro jatropha explants 26 days after inoculation in Murashige and Skoog (MS) basal medium with different concentrations of alpha-naphthalene acetic acid (NAA) and 6-Benzylaminopurine (BAP). Within each plant growth regulator, bars labeled with the same uppercase letter for NAA or lowercase letter for BAP are not significantly different $(P=0.01)$. 
A

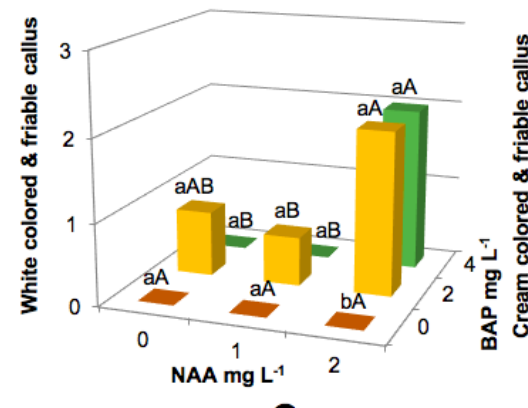

C

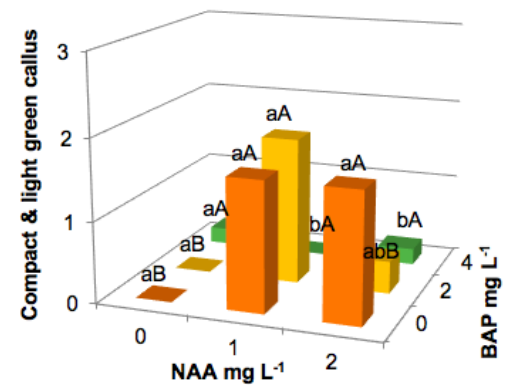

B

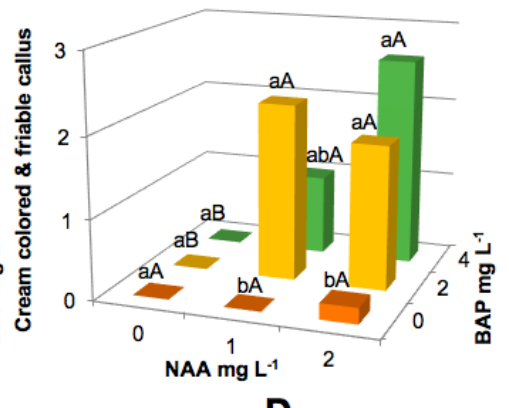

D

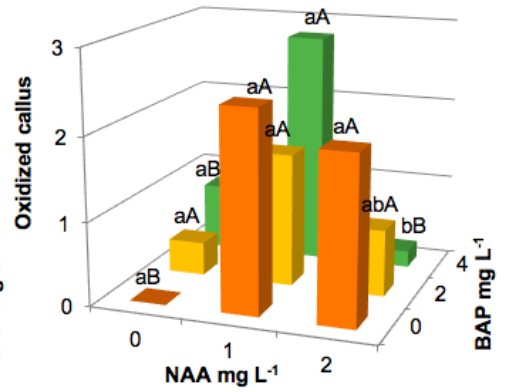

Fig 3. Calli formation from in vitro jatropha explants inoculated under different levels of BAP and NAA for 46 days and transferred to Murashige and Skoog (MS) basal medium (under dark conditions for 30 days). Within each plant growth regulator, bars labeled with the same uppercase letter for NAA or lowercase letter for BAP are not significantly different $(P=0.01)$.

Through the second assessment, performed in 26 days-old calli, we observed increased induction of both white colored and cream colored and friable calli throughout the time. These increments in callus induction were directly proportional to PGRs concentration and such calli grew profusely and possessed high regenerative potential. Similarly, Rajore and Batra (2007) highlights calli induction from leaf explants on MS basal medium supplemented with NAA $\left(1 \mathrm{mg} \mathrm{L}^{-1}\right)$ and BAP $\left(5 \mathrm{mg} \mathrm{L}^{-1}\right)$. The efficiency of micropropagation systems is determined by the rate of in vitro shoot production, which is directly influenced by plant growth regulators (PGR). In this way, combination of 6Benzylaminopurine (BAP) and other PGRs like 1Naphthaleneacetic acid (NAA) have been used in most of research in tissue culture, many times resulting in callus cell proliferation (Ali et al., 2015, Kumar et al., 2015, Hossain et al., 2016). Our results agree with a recent report in literature observed by Kashyap et al. (2016). These researchers verified that incubation of culture tubes in dark supported callus development significantly. Although we have confirmed good reasonable induction of callus for this jatropha hybrid accession (Costa Rica x Mexico) using BAP and NAA, more similar researches are needed to develop an effective organogenesis protocol in these calli previously obtained. In this way, it has been reported that regeneration in J. curcas is highly genotype dependent (Kumar and Reddy, 2010; Kumar et al., 2010; Kumar et al., 2015). In addition, Pierik (1991) mentioned that petiole is a somatic tissue and plants raised from the petiole are more resistant to genetic variation. This variability is supported by the morphological evaluation reported in Nietsche et al. (2013). These authors evaluated 17 accessions of jatropha from the collection at the University of Florida and observed that the Mexican and Costa Rican accessions differed in reproductive characteristics.

Similar results to the present study were obtained by Shrivastava and Banerjee (2008). These authors observed that well-developed shoots of Jatropha curcas when transferred to $1 / 2 \mathrm{MS}$ medium fortified with NAA (1.0-4.0 $\left.\mathrm{mg} \mathrm{L}^{-1}\right)$ intermittent callus formation takes place and no roots were observed. In addition, Kumar et al. (2008) believe that least elongation observed in a medium containing BAP and NAA may be due to the profuse callusing at the basal end of proliferated shoots.

The present study possesses valuable data that can serve as complementary information for the continued improvement of in vitro micropropagation systems for $J$. curcas hybrid accessions. Once $J$. curcas has been through a domestication process, the development of suitable technology for rapid multiplication of this species is essential. According to Ali et al. (2015), the conventional method of propagation through seeds and cuttings will not meet the demand. Therefore, in vitro regeneration of $J$. curcas offers a powerful method to overcome the problem (Kalimuthu et al., 2007). In this experimental condition, the management of factors such as BAP, NAA, sucrose-supplemented MS medium or dark environment variations did not provide callus differentiation into shooting or rooting. Therefore, further studies are necessary to achieve a successful protocol for in vitro multiplication of these hybrid accessions. Additional studies should address the effects of different explants, MS strength and PGRs concentrations to improve callus morphogenesis initiation in this kind of genetic material.

\section{Materials and methods}

\section{Plant material and location}

Seeds collected from twelve 4-year-old J. curcas hybrid accession plants were used in this experiment. These plants were obtained from intraspecific crosses between Costa Rica and Mexico accessions, which presented the following accession codes: TREC 49 and TREC 33, respectively 
(Nietsche et al., 2013). Plants were selected from a jatropha field plot at the University of Florida's Tropical Research and Educational Center (TREC) $\left(25^{\circ} 50^{\prime} \mathrm{N}\right.$ and $80^{\circ} 50^{\prime} \mathrm{W}, 3.8 \mathrm{~m}$ above sea level), in Homestead, FL, USA.

\section{Seed sterilization and germination in the $1^{s t} M S$ media preparation}

We conducted three different media preparation for jatropha cultivation, according to its needs during in vitro establishment. The first one was used only for seeds germination and initial seedling growth. In the second media, we used small sections of the seedlings produced to obtain callus induction. Finally, we transferred these calli cultures produced from second to third media looking for a possible cell differentiation and organogenesis.

Seeds were washed in distilled water and surface sterilized with 1\% Alconox (Alconox, New York, NY) solution followed by three successive distilled water rinses. Seeds were transferred to a laminar flow hood and were sterilized with $3 \%$ sodium hypochlorite for $5 \mathrm{~min}$ followed by three 3 min rinses in sterilized distilled water (Vendrame and Pinares, 2013).

After sterilization, testa was then removed from seeds (Danso et al., 2011) and the rest (cotyledon + embryo) were placed in magenta G-7 vessels (Magenta Corp., Chicago, IL) containing MS basal culture medium (Murashige and Skoog, 1962) solidified with $7 \mathrm{~g} \mathrm{~L}^{-1}$ agar (Fisher ${ }^{\circledR}$, Chicago, IL, USA) for germination.

The medium $\mathrm{pH}$ was adjusted to 5.7 before autoclaving at $121{ }^{\circ} \mathrm{C}$ for $15 \mathrm{~min}$ at $1.2 \mathrm{~kg} \mathrm{~cm}^{2}$. In vitro seed cultures were maintained under controlled environmental conditions; $27 \pm$ $2{ }^{\circ} \mathrm{C} ; 520 \mu \mathrm{mol} \mathrm{m} \mathrm{m}^{-2} \mathrm{~s}^{-1} ; 16 / 8$ light/dark using Philips ${ }^{\circledR}$ LED top lighting.

Two weeks after germination, when cotyledons and leaves had expanded, hypocotyl explants were subdivided into $2 \mathrm{~cm}$ sections and transferred to a MS basal medium supplemented with different combinations of PGRs.

\section{MS basal media with BAP or NAA ( $2^{\text {nd }}$ media preparation $)$}

The MS media with BAP and NAA were used as a callus induction media and were prepared for 6 replicates of each hormone concentration. The BAP (as cytokinin) and NAA (as auxin) concentrations were $0 ; 2$ or $4 \mathrm{mg} \mathrm{L}^{-1} \mathrm{BAP}$ and $0 ; 1$ or $2 \mathrm{mg} \mathrm{L}^{-1} \mathrm{NAA}$, respectively.

Cultures were maintained under the same controlled environmental conditions as described above. After 13 and 26 days cultures were evaluated for in vitro callus formation. The calli obtained per jar were classified through visual assessments in white colored and friable, cream colored and friable, compact and light green or oxidized callus.

\section{MS basal media under dark conditions $\left(3^{\text {rd }}\right.$ media preparation)}

After the second evaluation of callus formation (26 days after inoculation) we transferred the white colored and friable ones to a MS basal media. These jars were left under dark conditions for 30 days in order to observe if could be achieved successful organogenesis in these callus cultures (Biratar et al., 2012; Costa et al., 2015). Thereafter, we carried out the classification of them according to the four types mentioned above.

\section{Experimental design}

The experimental design was a factorial arrangement $3 \times 3$, which consisted of three BAP $\left(0 ; 2\right.$ or $\left.4 \mathrm{mg} \mathrm{L}^{-1}\right)$ and NAA $(0$; 1 or $2 \mathrm{mg} \mathrm{L}^{-1}$ ) concentrations added to the MS basal media. These combinations resulted in nine treatments, with 6 replicates of 5 shoots per treatment. Therefore, a total number of 45 jars and 270 calli were used in this research. Data was transformed using $\sqrt{x}+0.5$ and analyzed using analysis of variance (ANOVA) through the F test. Means were compared using Tukey test at $\alpha=0.01$. The original values are presented on figures.

\section{Conclusion}

Our results suggest that BAP $\left(2 \mathrm{mg} \mathrm{L}^{-1}\right)$ and NAA $\left(1 \mathrm{mg} \mathrm{L}^{-1}\right)$ combined can be used for in vitro callogenesis of $J$. curcas hybrid accession and that it can be adapted to a large-scale in vitro mass production system or to support biotechnological protocols.

\section{Acknowledgments}

The authors thank the Coordination for the Improvement of Higher Education Personnel (Coordenação de Aperfeiçoamento de Pessoal de Nivel Superior - CAPES, Brazil) and the University of Florida for providing funding to support this project.

\section{References}

Ali S, Afzal A, Usman M (2015) Micropropagation of Jatropha curcas L. Int J Biol Biotech. 12:29-38.

Biradar S, Waghmare V, Pandhure N (2012) In vitro callus and shoot induction in Jatropha curcas (Linn.). Trends Life Sci. 1:38-41.

Costa JL, Silva ALL, Bier MCJ, Brondani GE, Gollo AL, Letti LAJ, Erasmo EAL, Soccol CR (2015) Callus growth kinetics of physic nut (Jatropha curcas L.) and content of fatty acids from cude oil obtained in vitro. Appl Biochem Biotechnol. 176:892-902.

Danso KE, Afful NT, Annor C, Amoatey HM (2011) In vitro regeneration of Ricinus communis L. and Jatropha curcas L. for biofuel production. Biotechnol. 10:400-407.

Dikavara BN, Upadhyaya HD, Wani SP, Laxmipathi Gowda CL (2010) Biology and genetic improvement of Jatropha curcas L.: A review. Ap Energ. 87:732-742.

Hossain ABMF, Haq I, Ibrahim NA, Aleissa MS (2016) Callus cell proliferation from broccoli leaf slice using IBA and BAP in vitro culture: Its biochemical and antioxidant properties. Data in Brief. 6:214-220.

Ismail IB, Mustapha Y, Aliyu (2013) Micropropagation as a tool for experimental breeding, crop production and crop improvement. Glo Adv Res J Agric Sci. 2:307-314.

Jose J, Nimisha K, Anu MA, Nambisan P (2012) Evaluation of somaclonal variation in callus cultures of Jatropha curcas maintained on different hormonal combination using RAPD makers. World J Agric Sci. 8:616-623.

Kalimuthu K, Paulsamy S, Senthilkumar R, Sathya M (2007) In vitro propagation of the biodiesel plant Jatropha curcas L. Plant Tiss Cult and Biotech. 17:137-147.

Kashyap S, Kapoor N, Kale RD (2016). Coscinium fenestratum: callus and suspension cell culture of the endangered medicinal plant using vermicompost extract and coelomic fluid as plant tissue culture media. Am J of Pl Sci. 7:899-906. 
Kumar N, Pamidimarri SDVN, Kaur M, Boricha G, Reddy MP (2008) Effects of $\mathrm{NaCl}$ on growth, ion accumulation, protein, proline contents, and antioxidant enzymes activity in callus cultures of Jatropha curcas. Biol. 63:378-382.

Kumar N, Reddy MP (2010) Plant regeneration through the direct induction of shoot buds from petiole explants of Jatropha curcas: a biofuel plant. Ann Appl Biol. 156:367375.

Kumar N, Vijay Anand KG, Reddy MP (2010) Shoot regeneration from cotyledonary leaf explants of Jatropha curcas: a biodesel plant. Acta Physiol Plant. 32:917-924.

Kumar S, Kumar V, Sharma MK, Kumar N, Kumar A, Tomar KPS, Sharma SK, Singh MK, Sengar RS, Jaiswal N (2015) Effects of different plant growth regulators on in vitro callus induction in physic nut (Jatropha curcas L.) $\mathbf{J}$ Appl and Nat Sci. 7:30-37.

Maghuly F, Jankowicz-Cieslak J, Pabinger S, Till BJ (2015). Geographic origin is not supported by the genetic variability found in a large living collection of Jatropha curcas with accessions from three continents. Biotechnol J. 10:536-551.

Mohajer S, Taha RM, Khorasani A, Yaacob JS (2012) Induction of different types of callus and somatic embryogenesis in various explants of Sainfoin (Onobrychis sativa). Aust J Crop Sci. 6:1305-1213.

Moniruzzamana M, Yaakob Z, Khatuna R (2016) Biotechnology for Jatropha improvement: A worthy exploration. Renew Sust Energ Rev. 54:1262-1277.

Murashige T, Skoog F (1962) A revised medium for rapid growth and bio-assays with tobacco tissue cultures. Physiol Plant. 15:473-497.
Nietsche S, Vendrame WA, Crane JH, Pereira MCT (2013). Assessment of reproductive characteristics of Jatropha curcas L. in south Florida. GCB Bioen. 6:351-359.

Pan J, Fu Q, Zeng-Fu XU (2010) Agrobacterium tumefaciens-mediated transformation of biofuel plant $J$. curcas using kanamycin selection. Afr $\mathrm{J}$ of Biotechnol. 9:6477- 6481.

Parthiban, KT, Kirubashankkar R, Paramathma M, Subbulakshmi V, Thiyagarajan P, Vennila S, Sujatha M, Durairasu P (2011) Genetic association studies among growth attributes of jatropha hybrid genetic resources. Int J Plant Breed Genet. 5:159-167.

Pecina-Quintero V, Anaya-Lopez JL, Colmenero AZ, Garcia NM (2011) Molecular characterisation of Jatropha curcas L. genetic resources from Chiapas, México through AFLP markers. Biomass Bioenerg. 35:1897-1905.

Pierik RLM (1991) Commercial aspects of micropropagation. In: Prakash JK, Pierik RLM (Eds), Horticulture - New Technologies and Applications. Kluwer Academic Publishers, Dordercht, The Netherlands.

Rajore S, Batra A (2007) An alternative source for regenerable organogenic callus induction in Jatropha curcas. Ind J Biotech. 6:545-548.

Santos DN, Ferreira JL, Pasqual M, Generoso AL, Setotaw TA Cançado GMA Vendrame WA (2016). Population structure of jatropha and its implication for the breeding program. Genet Mol Res. 15:1-11.

Shrivastava S, Banerjee M (2008) In vitro clonal propagation of physic nut (Jatropha curcas L.): Influence of additives. Intern J Integr Biol. 3:73-79.

Vendrame VA, Pinares A (2013) Characterizing parameters of Jatropha curcas cell cultures for microgravity studies. Adv Space Res. 51:2069-2074. 